\title{
Artigo de Revisão \\ O TRABALHO DO PROFISSIONAL DE NÍVEL MÉDIO DE ENFERMAGEM NOS NOVOS DISPOSITIVOS DE ATENÇÃO EM SAÚDE MENTAL
}

Sonia Regina Zerbetto ${ }^{1}$

MariaAlice Ornellas Pereira ${ }^{2}$

Zerbetto SR, Pereira MAO. O trabalho do profissional de nível médio de enfermagem nos novos dispositivos de atenção em saúde mental. Rev Latino-am Enfermagem 2005 janeiro-fevereiro; 13(1):112-7.

O estudo consiste em levantamento bibliográfico abrangendo o profissional de nível médio de enfermagem nos serviços alternativos de saúde mental, com o objetivo de refletir sobre o seu trabalho, considerando o modelo psicossocial e as suas ações de intervenção na assistência, baseadas no referencial teórico de tecnologias leves. Observou-se que há um processo de transição do modelo tradicional ao psicossocial; do tecnicista à satisfação das necessidades do usuário e a importância de rever o processo de formação dessa categoria profissional, salientando a nova postura do enfermeiro-professor que deve buscar ensino crítico-reflexivo e direcionado para os ideais da Reforma Psiquiátrica.

DESCRITORES: enfermagem psiquiátrica; saúde mental; cuidados de enfermagem

\section{THE WORK OF THE MID-LEVEL NURSING PROFESSIONAL IN THE NEW MENTAL HEALTH CARE SERVICES}

The study consists of a bibliographic survey covering mid-level nursing professionals in alternative mental health services, with the objective to reflecting on their work, considering the psychosocial model and its care intervention actions, based on the theoretical reference framework of the so-called "light technologies". It was observed that there is a transition process from the traditional to the psychosocial model, from a technical model to the model of satisfying user needs and the importance of reviewing these professionals' training process, pointing out a new attitude of the nurse-teacher, who should aim for critical-reflective teaching that is aimed at the ideals of the Psychiatric Reform.

DESCRIPTORS: psychiatric nursing; mental health; nursing care

\section{EL TRABAJO DEL PROFESIONAL DE ENFERMERÍA DE NIVEL MEDIO Y LOS NUEVOS SERVICIOS DE ATENCIÓN EN LA SALUD MENTAL}

El estudio se trata de un inventario bibliográfico que abarca al profesional de enfermería de nivel medio en los servicios alternativos de salud mental, con objeto de reflexionar sobre su trabajo, teniéndose en cuenta el modelo psicosocial y sus acciones de intervención en la atención, basadas en el referencial teórico de tecnologías livianas. Se observa que hay un proceso de transición del método tradicional al psicosocial y del técnico a la satisfacción de las necesidades del usuario y la importancia de reconsiderar el proceso de formación de esta categoría profesional, resaltando una nueva postura del enfermero(a)-profesor(a) que busca una enseñanza crítica y reflexiva en dirección a los ideales de la Reforma Psiquiátrica.

DESCRIPTORES: enfermería psiquiátrica; salud mental; atención de enfermería

\footnotetext{
${ }^{1}$ Enfermeira, Doutoranda da Escola de Enfermagem de Ribeirão Preto, da Universidade de São Paulo, Centro Colaborador da OMS para o desenvolvimento da pesquisa em enfermagem, Docente do Senac de São Carlos, e-mail: enfemi@terra.com.br; ${ }^{2}$ Enfermeira, Professor Doutor da Faculdade de Medicina da Universidade Estadual Paulista de Botucatu, e-mail: malice@fmb.unesp.br
} 


\section{INTRODUÇÃO}

Para uma reflexão sobre o trabalho do auxiliar e do técnico de enfermagem nos novos dispositivos institucionais de atenção em saúde mental, ou seja, Núcleo de Atenção Psicossocial (NAPS), Centro de Atenção Psicossocial (CAPS) e Unidades Básicas de Saúde com equipes de saúde mental e serviços de atendimento à saúde mental em hospitais gerais, faz-se necessário reportar-se a dois pontos importantes: o modelo psicossocial como tendência nas políticas de saúde mental, 0 qual busca prática substitutiva ao modelo asilar e às novas ações de intervenção na assistência. Afinal, como vem sendo efetivado o cuidado prestado por essas categorias profissionais nesse novo modelo assistencial de saúde mental?

Observa-se que as instituições acima citadas sofrem influências do modelo capitalista de produção e, portanto, as práticas de seus trabalhadores podem carregar características de um trabalho fragmentado técnico e socialmente ${ }^{(1)}$.

No caso da enfermagem, a ideologia capitalista proporcionou a divisão de tarefas, sendo o cuidado de supervisão, administração e ensino destinados a enfermeiros e os cuidados diretos (banho, medicação, curativos, alimentação, etc.) a auxiliares e técnicos de enfermagem. Aatividade profissional da enfermagem é caracterizada pela divisão técnica e social do trabalho, fragmentando as suas atividades em tarefas, procedimentos e atribuições, que são designadas aos outros componentes da equipe ${ }^{(2)}$.

Em relação à saúde mental, historicamente, a assistência de enfermagem é marcada por práticas de violência, tanto explícitas como veladas, agressões físicas, poder do profissional sobre o usuário, repressão moral, inclusão social anômala e com o predomínio referencial de um modelo biológico e psicologizante, priorizando-se como único local de tratamento, o manicômio.

Portanto, atualmente, espera-se que 0 trabalho dessa categoria profissional, nos novos serviços substitutivos, contemple outras maneiras de agir e esteja comprometido com as idéias da Reforma Psiquiátrica. O novo enfoque da saúde mental visa a reconstrução do sujeito, preservando sua subjetividade, sua história de vida e suas relações interpessoais, buscando romper com mecanismos que podem perpetuar a marginalização do doente e não reconhecê-lo como cidadão.

\section{OBJETIVO}

Refletir sobre o trabalho do profissional de nível médio de enfermagem nos serviços substitutivos de saúde mental.

\section{REFERENCIAL TEÓRICO-METODOLÓGICO}

O trabalho é uma atividade que tem em sua essência o objetivo de alterar o estado natural dos materiais existentes no meio ambiente para serem melhor utilizados ${ }^{(3-4)}$. Assim, o homem ao realizar o trabalho, atua sobre essa natureza, transformando-a para satisfazer suas necessidades, mas, ao mesmo tempo, se transforma, pois ele é produto de seu trabalho, isto é, ele produz algo que já estava, antecipadamente, idealizado em sua imaginação, o que o diferencia de outros animais. Dessa forma, o homem realiza um trabalho consciente e com uma ação intencional (condições subjetivas) para produzir a sua própria existência, seja uma produção material (coisas/objetos) ou de bens/produtos simbólicos para satisfação de suas necessidades.

O homem, através do seu trabalho, relaciona-se com outros homens e é transformado por essas relações sociais e por outras determinações que ocorrem nesse processo.

No que se refere ao trabalho em saúde, o seu produto final não se resume imediatamente a uma mercadoria, ou seja, um bem material, que tem finalidade de acumular capital e servir de meio de produção da mais-valia. O trabalho em saúde atende às necessidades do homem, as quais não são naturais, mas histórica e socialmente determinadas. Assim, o homem é um ser social e sujeito da história, pois ele é o criador de sua própria história, mas como indivíduo concreto $^{(5)}$.

O trabalho em saúde produz atos de saúde que têm a capacidade de intervir em sua problemática, modificando-a e levando à produção de um resultado que é a satisfação de uma necessidade/ direito do usuário. Conclui-se, assim, que esse processo permite a produção de saúde ${ }^{(6)}$. No campo da saúde, o objeto de trabalho último é o ser humano que precisa de ações de saúde, sejam de prevenção, promoção, reabilitação, socialização, proteção e outras, que atendam as necessidades de saúde dos indivíduos e não um procedimento técnico.

O trabalho em saúde é centrado no trabalho vivo em ato e não pode ser capturado na lógica do trabalho morto, expresso somente nos equipamentos/máquinas (tecnologia dura) e nos saberes estruturados (tecnologia leve-dura), pois no campo das intervenções assistenciais há abordagem assistencial de um trabalhador de saúde junto a um usuário/cidadão, em um processo de relações, que envolve tecnologia de relações (tecnologia leve) de encontros de subjetividades, de produção de vínculo, autonomização (aqui definida como a capacidade do indivíduo de governar o modo de conduzir a sua própria vida) e acolhimento. A tecnologia dura é representada pelos equipamentos tecnológicos do tipo máquinas, normas e estruturas organizacionais e a tecnologia leve-dura, sendo que a leve relacionase com o saber que as pessoas adquirem e se apropriam no modo de 
pensar e atuar sobre os casos de saúde, e de dura, por exigir um saber-fazer estruturado, organizado, que normaliza e é normalizado ${ }^{(7)}$.

Dessa maneira, a interligação desses três tipos de tecnologia pode produzir uma qualidade no sistema de assistência e atenção à saúde, pois busca atender o problema de saúde do usuário/cidadão, proporcionando-lhe maior autonomia para conduzir a sua vida cotidiana, produzindo saúde e minimizando o sofrimento humano.

Utilizando-se dos conceitos de tecnologia dura, leve-dura e leve, enfoca-se aqui a tecnologia leve, pois as outras duas são, geralmente, mais efetivadas por esses profissionais, ou seja, a primeira em que o profissional se utiliza de equipamentos tecnológicos para examinar o indivíduo e a segunda por se respaldar em um saber estruturado para fazê-lo (representados pelas disciplinas que operam em saúde como a clínica médica, odontologia, epidemiologia, psicofarmacologia e outras) $)^{(6)}$.

Outro conceito em que houve respaldo para a reflexão do trabalho do profissional de nível médio de enfermagem, foi o modelo psicossocial. De acordo com esse modelo, investe-se na reconstituição do sujeito que está sofrendo psiquicamente, portanto, o indivíduo participa de seu tratamento e o objetivo não é a remissão total da sintomatologia. A cura nem sempre é efetivada, mas, sim, a produção de vida nas pessoas. Os conflitos e o sofrimento psíquico fazem parte da existência do sujeito, da sua família e da sociedade, o que requer a participação de todos. O sujeito não é só o agente dos conflitos, mas um indivíduo que se reconhece nesse processo, se reposiciona subjetivamente e busca possibilidades de mudanças, possibilitando a sua reinserção e não mera adaptação social ${ }^{(1)}$.

Os meios de trabalho são os recursos psicoterapêuticos, socioterapêuticos, farmacoterapêuticos, laborterapêuticos e os socioculturais que buscam à integração do indivíduo ${ }^{(1)}$.

Quanto ao relacionamento da instituição com a clientela, considera-se a possibilidade de favorecer um espaço de interlocução através de seus agentes, resgatando as subjetividades, tanto dos usuários/clientes como dos trabalhadores. Torna-se um espaço de escuta e fala da população, o que requer novas abordagens, inclusive reconhecer e priorizar as necessidades das pessoas, possibilitando intersubjetividades e bases para a singularização.

Nesse novo modo de cuidar do sujeito, a equipe interprofissional é importante, pois deixam de existir os "especialistas" e a sua visão se amplia para uma ação integral, ou seja, a equipe utiliza todos os recursos disponíveis (as artes, a música, a literatura e outros mais). Portanto, deve-se escutar a fala de pessoas que estão sofrendo e estar aberto para os seus simbolismos. Rompe-se a congruência - saber é poder.

Explicitados os conceitos do referencial teórico, é importante salientar que este estudo consistiu num levantamento bibliográfico, tendo como base teses e periódicos que enfocaram o trabalho de auxiliares e técnicos de enfermagem nos serviços substitutivos de saúde mental. Foram utilizados, como fonte de busca bibliográfica, os bancos de dados da Universidade de São Paulo - DEDALUS, através do site http://www.usp.br/sibi, usando-se como descritores: enfermagem em saúde mental, auxiliar e técnicos de enfermagem, enfermagem psiquiátrica.

\section{RESULTADOS E DISCUSSÃO}

Os estudos que retratam o processo de trabalho nos serviços alternativos, em sua maioria, enfocam como objeto de trabalho dos profissionais a doença mental, ou seja, o comportamento patológico do indivíduo, sendo os instrumentos de trabalho a ação medicamentosa, a consulta médica, atividades em grupo e individuais, tendo como finalidade da assistência a remissão da sintomatologia. Há predominância do modelo biológico como referencial teórico na prática diária ${ }^{(8-10)}$

Outras pesquisas enfocam novas abordagens, o encontro de um novo "objeto" e uma nova organização do trabalho. O olhar do profissional se volta para a pessoa que sofre e tem uma história de vida, uma biografia, ou seja, é um cidadão com direitos e deveres. Uma pessoa com sua singularidade e que deseja ser escutada, acolhida, compreendida em uma relação que se pauta no vínculo. $A$ organização do trabalho não é embasada nos princípios dos saberes e das especialidades de cada categoria profissional, portanto, rompe a hierarquia rígida do poder/saber ${ }^{(11-12)}$.

O auxiliar e o técnico de enfermagem assumem outra postura quando estabelecem relação com o usuário (tecnologia leve), ou seja, estão atentos à problemática de saúde do indivíduo que busca ajuda e, portanto, o profissional pode utilizar-se do acolhimento como instrumento de intervenção. A informação trazida pelo usuário é ouvida e interpretada, pois, a falar de si mesmo, de sua história de vida, ele vai resgatar a si mesmo, podendo o profissional ajudá-lo a se perceber, a se re-posicionar subjetivamente, propondo ajuda aos seus conflitos e apoiando-o nos seus desejos e sonhos, para resgatar a sua vida cotidiana, dando, assim, um primeiro passo para uma intervenção reabilitativa.

Os artigos pesquisados salientam que a maioria da categoria de nível médio de enfermagem não teve formação suficiente na área de saúde mental e psiquiátrica, tanto na questão teórica como prática. Outro ponto ressaltado pela literatura é que esses profissionais acabam adquirindo conhecimentos que fundamentam sua prática, no cotidiano do processo de trabalho ${ }^{(11,13-17)}$.

Outro estudo, em que se objetivou buscar a captação, 
problematização e análise da ação de saúde produzida pelo agente de enfermagem de nível médio, em um serviço substitutivo de saúde mental (CAPS), num caminhar do materialismo histórico e dialético, observou que esses profissionais não conseguiam identificar o local de trabalho como espaço de formação, apesar de serem atores de ações produtoras de saúde. O foco do cuidado em si direcionou-se para a necessidade de saúde dos usuários, sendo que os profissionais desenvolveram atitudes solidárias, afetivas, psicoterapêuticas, reabilitatórias, de proteção (inclusive com a equipe e a instituição) e farmacológicas. Salientou que a prática social em construção pode ser um espaço produtor de saber se o fazer for problematizado, refletido criticamente e consciente. Essa pesquisa também demonstrou que os agentes de enfermagem de nível médio ainda sustentam um pensamento cativo da subalternidade, ou seja, compreendendo que o saber está depositado no fazer dos profissionais de formação superior ${ }^{(17)}$.

A mesma obra, citada anteriormente, baseando-se no referencial teórico de Merhy, principalmente na tecnologia leve, salienta que, no caso da enfermagem, o relacionamento terapêutico (como instrumento) e a comunicação terapêutica (como técnica) devem ser utilizados.

A idéia acima é questionada por algumas autoras ${ }^{(18)}$, as quais consideram que, em cursos de graduação do enfermeiro, o importante é enfatizar o relacionamento interpessoal e profissional e deixar 0 relacionamento terapêutico para contexto de especialização, por exigir conhecimento mais aprofundado.

Outras pesquisas também ressaltam que o profissional auxiliar de enfermagem, que atua em instituições substitutivas, ainda identifica e executa uma atividade limitada às técnicas de enfermagem e ao relacionamento interpessoal ${ }^{(11,19)}$.

No referente ao agente de saúde de nível médio, outro estudo ${ }^{(20)}$ pôde constatar que tal categoria profissional não tem acesso a esses conceitos teóricos e nem práticos durante a sua formação profissional. Às vezes, o conteúdo de Relacionamento Interpessoal pode ser abordado em cursos de ensino técnico de enfermagem, mas o é de forma fragmentada, teórica, sem ser refletido em campo prático, o que leva ao desconhecimento de sua aplicabilidade como habilidade no cotidiano de trabalho e, quando utilizado, está somente associado às realizações de procedimentos técnicos.

Acredita-se que, no ensino dos auxiliares e técnicos de enfermagem, se deve também dar noções teóricas sobre 0 relacionamento interpessoal e ajudá-los a refletir em campo de estágio sobre a sua execução, principalmente que tal instrumento não pode ser valorizado somente durante a realização dos procedimentos técnicos.

Há, portanto, algumas diretrizes norteadoras do projeto de intervenção nos novos dispositivos de saúde mental, que podem se tornar eixos condutores de todo um trabalho, ou seja, o resgate de singularidade, reconstrução da história, produção de subjetividade e construção de cidadania do indivíduo. Na prática cotidiana, nas instituições inventadas, os profissionais criam e inventam instrumentos e meios mediadores nas relações, que tentam romper relações de tutela totalizantes, ou seja, que só reconhecem o indivíduo como incapaz, inábil e perigoso. O objetivo é superar esse modo de relação e buscar o poder contratual, isto é, dinamizar os recursos/ potencialidades (materiais, psíquicos, culturais, físicos) que a pessoa possui para participar na diversidade da rede de interações sociais e conduzir a sua vida de acordo com as situações enfrentadas e vivenciadas $^{(12)}$.

No modelo psicossocial, os trabalhadores de nível médio em enfermagem, ao interagirem com o usuário e seus familiares, precisam lembrar que essa relação envolve um sujeito em sua complexidade, portanto emerge a necessidade de um plano terapêutico individualizado. Uma das buscas no trabalho de saúde mental é minimizar a dor e 0 sofrimento das pessoas, produzir saúde, atendendo e satisfazendo as suas necessidades, sejam elas biológicas, sociais, econômicas, psicológicas ou culturais.

Assim, o profissional se torna polivalente, ou seja, as suas atividades transcendem a área específica de sua formação, rompe com a questão do aspecto técnico, evita a fragmentação do processo terapêutico, assume a responsabilidade individual no acompanhamento do caso, trabalha a aproximação do usuário e a coleta de sua história de vida, o que pode se traduzir em intervenção de responsabilidade e afetividade.

O cuidar de uma pessoa envolve a responsabilidade, que se efetiva ao assumir a globalização das necessidades do indivíduo. Isso também requer movimentação do serviço, que acaba se confrontando ao elaborar respostas que atendam às exigências da demanda $^{(12)}$

Nos serviços de atenção psicossocial, o atendimento não se limita somente ao momento de crise, mas na continuidade da vida do usuário, significando a busca da reabilitação psicossocial. Reabilitar é construir, ou reconstruir sentimento real aos direitos de cidadania, 0 exercício progressivo desses direitos, a possibilidade de vê-los reconhecidos e a capacidade de praticá-los.

O indivíduo deve ser ajudado a restabelecer suas relações afetivas e sociais, reconquistar seus direitos na comunidade e o seu poder social. As estratégias de intervenção devem estar delineadas em um projeto terapêutico, o qual é discutido, elaborado, realizado e avaliado por todos os membros da equipe assistencial, podendo ser modificável de acordo com a evolução do usuário. Os objetivos gerais da intervenção devem ajudar o indivíduo a perceber seus problemas pessoais, familiares, de trabalho, econômicos, sociais e culturais, buscar 
a autonomia afetiva-material-social do sujeito e o incremento da incorporação desse na vida de relação social e política ${ }^{(21)}$.

Dessa maneira, a intervenção passa a trabalhar, paralelamente, a noção de cidadania do usuário e também baseado no tripé casa/trabalho/relações sociais, portanto, torna o usuário receptor de seus direitos e um participante ativo na construção de sua própria reabilitação e de seu cotidiano como sujeito social. Assim, esse novo olhar para a reabilitação exige do profissional da enfermagem maior flexibilidade, criatividade, iniciativa, participação, visão crítica e analítica da realidade, abertura para conhecimentos de outras áreas da ciência e aprimoramento na comunicação e relações interpessoais, trabalho em conjunto que busca o compartilhamento de decisões e 0 exercício do cuidado ampliado ${ }^{(22)}$.

\section{CONSIDERAÇÕES FINAIS}

Este estudo, leva a pensar que o trabalho do profissional auxiliar e técnico de enfermagem vai além de mera "habilidade técnica" e passa a ter um outro papel num cenário também diferente. Tais categorias necessitam ser sujeitos sociais participativos, críticos, inovadores, transformadores e inseridos numa sociedade que também está se modificando, mesmo que, às vezes, de maneira lenta.

O modo de trabalhar modifica-se e exige novos conceitos e práticas em saúde mental para objetivar a transformação nessa área. O profissional pode articular os seus conhecimentos teórico-práticos e propor estratégias de intervenção que favoreçam a integração e fortalecimento de uma relação ética e solidária entre o próprio serviço e a comunidade onde esse está inserido.

Percebe-se que o cuidar dos profissionais de nível médio ainda está em processo de transição, ou seja, de um modelo tecnicista e de relação de poder a um modelo que busca satisfazer as necessidades do usuário, sem se limitar a procedimentos técnicos, mas criando ações de intervenção reabilitatórias, psicoterapêuticas (Saraceno, em seu manual de estratégias de ação no campo psicossocial, define tal termo no contexto de uma relação interpessoal entre usuário/ profissional em que não há um referencial teórico específico, mas permeiam afetividades, respeito, acolhimento), integralizadoras e acolhedoras, tanto no referente ao usuário como aos profissionais de saúde.

Acredita-se que, ao mesmo tempo em que o cuidado é feito integral e globalizante ao usuário de saúde mental, também leva à reflexão sobre quem presta esse cuidado. Essa categoria profissional, que representa um contigente importante da força de trabalho da enfermagem, em muitos momentos é desvalorizada e excluída de muitos processos decisórios, dentro da própria equipe a qual pertence, tendo o seu "poder contratual" desrespeitado e "tutelado de forma institucionalizada". Aqui, pode-se dizer que ela acaba somente recebendo e respeitando as normas e ordens pré-estabelecidas e decididas, sem a sua participação, o que incorre na necessidade urgente de transformação do próprio enfermeiro.

Nesse momento, ressalta-se a importância do processo de desinstitucionalização do enfermeiro, ou seja, ele deve rever suas posturas, seus saberes teóricos e práticos que mantêm a exclusão social não só do usuário, mas do auxiliar e técnico de enfermagem. 0 importante é a ênfase na relação social (usuário/profissionais da saúde/ comunidade) e a busca da ruptura de mecanismos perpetuadores da marginalização dos sujeitos, correndo o risco de não reconhecê-los como cidadãos.

Assim, o processo de formação desse profissional requer um novo olhar. Chama-se a atenção dos enfermeiros-professores, os responsáveis pelo seu processo formativo, enfatizando-se que isso requer mudança de concepção do "objeto" da saúde mental e a necessidade de descontruir/reconstruir esse novo jeito de trabalhar nesse novo paradigma psicossocial. É necessário que o enfermeiroprofessor articule conhecimentos de outras áreas da ciência e exercite outros modos de relacionamentos, que não sejam os de punir, vigiar, controlar e disciplinar. Que o docente utilize os serviços alternativos, tais como os CAPS, como espaços de ensino-aprendizagem e que 0 fazer vivenciado (do contexto) pelo aluno seja problematizado e analisado, juntamente com as suas estratégias utilizadas, para proporcionar uma relação única entre teoria e prática, evitando-se a ação mecanizada/reiterativa/alienada e obtendo-se ação reflexiva/ consciente, portanto uma práxis.

A rede de relações sociais requer atitudes de acolhimento, responsabilidade, aproximação, disponibilidade de escutar, afetividades, estabelecer mediações, dialetizar conflitos, tanto para o usuário da saúde mental como no cotidiano escolar.

O docente necessitará articular a finalidade de ensino com sua ação de ensinar, ou seja, ele precisa ver sentido social em suas ações, pois isso irá torná-lo crítico e consciente de sua missão educacional e histórica. 


\section{REFERÊNCIAS BIBLIOGRÁFICAS}

1. Rosa CA. O modo psicossocial: um paradigma das práticas substitutivas ao modo asilar. In: Amarante P. Ensaios: subjetividades, saúde mental, sociedade. Rio de Janeiro (RJ): Fiocruz; 2000. p.14168.

2. Almeida MCP, Rocha JSY. O saber de enfermagem e sua dimensão prática. São Paulo (SP): Cortez; 1986.

3. Braverman $\mathrm{H}$. Trabalho e gerência. In: Braverman $\mathrm{H}$. Trabalho e capital monopolista: degradação do trabalho no século XX. Rio de Janeiro (RJ): Guanabara; 1989. p. 47-81.

4. Ianni O, organizador. A produção da sociedade capitalista. In: Marx K. Sociologia. São Paulo (SP): Atica; 1979. p. 7-42.

5. Gonçalves RBM. Práticas de saúde: processo de trabalho e necessidades. São Paulo (SP): EDUSP; 1990.

6. Merhy EE, organizador. A perda da dimensão cuidadora na produção da saúde: uma discussão do modelo assistencial e de intervenção no seu modo de trabalhar a assistência. In: Reis AT, Santos AF, Campos CC, Malta DC, Merhy EE. Sistema Único de Saúde em Belo Horizonte: reescrevendo o público. São Paulo (SP): Xamã; 1998. p.103-20.

7. Merhy EE, Onocko R, organizadores. Agir em saúde: um desafio para o público. São Paulo (SP): HUCITEC; 1997.

8. Miron VL. Organização do trabalho em saúde mental em um serviço ambulatorial público de saúde. [Dissertação]. Ribeirão Preto (SP): Escola de Enfermagem de Ribeirão Preto/USP; 1993.

9. Barros S, Campos CMS. Reflexões sobre o processo de cuidar da enfermagem em saúde mental. Rev Esc Enfermagem USP 2000; 34(3):271-6.

10. Lima IMN. A assistência ambulatorial como alternativa à assistência hospitalocêntrica em saúde mental: um estudo de caso realizado no Centro de Saúde Escola da Faculdade de Medicina de Ribeirão Preto da Universidade de São Paulo. [Dissertação]. Ribeirão Preto (SP): Escola de Enfermagem de Ribeirão Preto/USP;2000.

11. Filizola CLA O trabalho em um Núcleo de Atenção Psicossocial do município de Santos (SP): resgatando desejos, reconstruindo projetos de vida em um tempo sem milagres. [Tese]. Ribeirão Preto (SP):Escola de Enfermagem de Ribeirão Preto/USP; 1999.

12. Nicácio MFS. O processo de transformação da saúde mental em Santos: desconstrução de saberes, instituições e cultura. [Dissertação]. São Paulo (SP): Pontíficia Universidade Católica de São Paulo; 1995. 13. Rocha RM. Enfermagem psiquiátrica: que papel é esse? Rio de Janeiro (RJ): Te Cora; 1994.

14. Kirschbaum DIR, OliveiraACS. Formação e dificuldades profissionais de auxiliares de enfermagem no campo da assistência psiquiátrica. Rev Paul Enfermagem 2001; 20(1):13-21.

15. Kirschbaum DIR. A participação da enfermagem em um projeto de desinstitucionalização. Anais do $10^{\circ}$ Congresso Mundial de Psiquiatria; 1996 Agosto 23-28; Madri; Espanha; 1996.

16. Chamma RC, Forcella HT. O cidadão com transtornos psíquico: reflexões sobre os direitos humanos e os direitos do paciente. Rev Esc Enfermagem USP 2001; 35(2):184-90.

17. Silva ALA. Enfermagem em saúde mental: a ação e o trabalho de agentes de enfermagem de nível médio no campo psicossocial. [Tese]. São Paulo (SP): Escola de Enfermagem/USP; 2003.
18. Barros S, Rolim MA. O ensino de enfermagem psiquiátrica e a lei do exercício profissional da enfermagem. Rev Latino-am Enfermagem 1996 jan-fev.; 4(1):47-54.

19. Koda MY. Da negação do manicômio à construção de um modelo substitutivo em saúde mental: o discurso de usuários e trabalhadores de um núcleo de atenção psicossocial. [Dissertação]. São Paulo (SP): Instituto de Psicologia/USP; 2002.

20. Ribeiro MILC. Relacionamento interpessoal no nível médio de enfermagem. [Dissertação]. Ribeirão Preto (SP): Escola de Enfermagem de Ribeirão Preto/USP; 2002.

21. Saraceno B, Asioli F, Tognoni G. Manual de saúde mental: guia básico para atenção primária. São Paulo (SP): Hucitec; 1997.

22. Machado AL, Martines WRV. Anais: Enfermagem e reabilitação psicossocial: vislumbrando o exercício de cidadania do doente mental. In: Labate RC, organizadora. Caminhando para a assistência integral. $5^{\circ}$ Encontro de Pesquisadores em Saúde Mental; $4^{0}$ Encontro de especialistas em Enfermagem Psiquiátrica; 1998. abril 29-30; Ribeirão Preto, São Paulo. Ribeirão Preto: Scala; 1998. p.107-16. 